\title{
Методика выделения и учета вековой вариации при проведении высокоточных геомагнитных наблюдений (на примере Алтайского геодинамического полигона
}

Кулешов Д. А., Дядьков П. Г., Плоткин В. В.

\begin{abstract}
Аннотация
УДК 550.389+550.384.3

Рассмотрена проблема выделения и учета вековой вариации геомагнитного поля на исследовательских геодинамических полигонах. Предложена методика выделения вековой вариации геомагнитного поля на участках земной поверхности с линейными размерами порядка 100 - 500 км на основе высокоточных данных геомагнитных наблюдений. По мнениям большинства исследователей источники вековой вариации находятся в жидком ядре и удалены от поверхности Земли не менее, чем на 3000 км. При этом размеры исследовательских полигонов составляют $~ 500$ км. Не вдаваясь в конфигурацию источника вековой вариации, ясно, что в силу различных глубин источников вековой вариации (в жидком ядре) и тектономагнитных аномалий (до границы Кюри 10 - 20 км) поверхность, представляющая собой пространственное изменение вековой вариации, должна обладать много меньшей кривизной, чем кривизна поверхности, представляющая пространственное изменение тектономагнитных аномалий. Таким образом, задача сводится к разделению полей от источников, находящихся на существенно разных глубинах. Построение полиномиальной поверхности, интерполирующей вековую вариацию, позволило произвести ее учёт с точностью порядка не хуже 0,5 нТл. Таким образом, задача сводится к разделению полей от источников, находящихся на существенно разных глубинах (региональные и локальные поля). Апробация методики произведена по данным ежегодных высокоточных геомагнитных наблюдений, выполненных на более чем 30 пунктах геодинамического полигона в Горном Алтае в период в 2004 - 2018 гг. Показано, что в случае Алтайского полигона (линейные размеры 120 км) для данного периода наблюдений в качестве поверхности, интерполирующей пространственное изменение вековой вариации, может использоваться поверхность второго порядка. Предложенная методика позволила произвести учёт и исключение вековой вариации из данных высокоточных магнитных наблюдений. Учет вековой вариации позволил выделить тектономагнитные аномалии величиной до 12 нТл, которые до этого в явном виде не проявлялись. Наблюдается пространственная приуроченность положительной аномалии величиной около 3 нТл к области сейсмодислокации Чуйского землетрясения 27.09.2003, Mw = 7.3.
\end{abstract}

\section{Ключевые слова:}

Ключевые слова: геомагнитное поле, вековая вариация, тектономагнетизм, Алтайский геодинамический полигон, методы интерполяции данных Key words: geomagnetic field, secular variation, tectonomagnetism, Altai geodynamic network, interpolate data methods 
УДК $550.389+550.384 .3$

\title{
МЕТОДИКА ВЫДЕЛЕНИЯ И УЧЕТА ВЕКОВОЙ ВАРИАЦИИ ПРИ ПРОВЕДЕНИИ ВЫСОКОТОЧНЫХ ГЕОМАГНИТНЫХ НАБЛЮДЕНИЙ (НА ПРИМЕРЕ АЛТАЙСКОГО ГЕОДИНАМИЧЕСКОГО ПОЛИГОНА)
}

\author{
Д.А. Кулешов ${ }^{1}$, П.Г. Дядьков ${ }^{1,2}$, В.В. Плоткин ${ }^{1}$ \\ 1 Федеральное государственное бюджетное учреждение науки Институт \\ нефтегазовой геологии и геофизики им. А.А. Трофимука Сибирского отделения \\ Российской академии наук; \\ 2 Федеральное государственное автономное образовательное учреждение высшего \\ образования «Новосибирский национальный исследовательский университет».
}

Предложена методика выделения и учёта вековой вариации геомагнитного поля на участках земной поверхности с линейными размерами порядка первых сотен километров. Необходимость выделения и учёта вековой вариации возникает при решении различных задач геофизики, включающих как собственно изучение ее параметров и особенностей в данном регионе, так и изучение источников магнитного поля, расположенных в земной коре (магнитные съемки и карты аномального поля) и их изменений во времени (тектономагнитные исследования). По мнениям большинства исследователей источники вековой вариации находятся в жидком ядре и удалены от поверхности Земли не менее, чем на 3000 км. В силу различных глубин источников вековой вариации (граница ядро-мантия) и аномалий с источниками в земной коре поверхность, представляющая собой пространственное изменение вековой вариации, должна обладать много меньшей кривизной, чем кривизна поверхности, представляющая пространственное изменение коровых аномалий. Таким образом, задача сводится к разделению полей от источников, находящихся на существенно разных глубинах (региональные и локальные поля). Апробация методики произведена по данным ежегодных высокоточных геомагнитных наблюдений, выполненных на более чем 30 пунктах геодинамического полигона в Горном Алтае в период в 2004 - 2018 гг. Показано, что в случае Алтайского полигона (линейные размеры 120 км) для данного периода наблюдений в качестве поверхности, интерполирующей пространственное изменение вековой вариации, может использоваться поверхность второго порядка. Применение данной методики позволило рассчитать пространственное распределение вековой вариации геомагнитного поля на исследуемом 
участке, а также выявить изменения аномального магнитного поля, источники которого расположены в литосфере. Одна из выделенных аномалий величиной около 3-х нТл, положительная, приурочена к области сейсмогенной дислокации Алтайского землетрясения 2003 г., М = 7.3. Вторая, отрицательная, расположена севернее дислокации и пространственно совпадает с районом Курайского хребта. До применения методики выделения и учёта вековой вариации данные аномалии в явном виде не проявлялись.

\section{ВВЕДЕНИЕ}

При проведении высокоточных геомагнитных наблюдений на специальных полигонах с целью изучения геодинамических и сейсмических процессов (тектономагнитные исследования) возникает проблема выделения и учёта вековой вариации геомагнитного поля [Дядьков и др., 1999]. В работах, посвященных оценкам тектономагнитных эффектов, вызванных магнитоупругими или электрокинетическими явлениями в земной коре, показано, что амплитуда этих эффектов, как правило, не превышает первых единиц нТл [Капица, 1955; Черняк Г.Я, 1976]. Отсюда следует актуальность выделения и учёта вековой вариации, величина которой может значительно превышать эти значения.

Вековой вариацией принято называть изменения элементов геомагнитного поля (ГМП) во времени, обусловленное процессами в земном ядре [Courtillot, Mouël, 1988]. В данной работе проводится исследование пространственного изменения вековой вариации ГМП за период 2004 - 2018 гг. в области Алтайского геодинамического полигона относительно базового контрольного пункта. При этом, используемая методика синхронных наблюдений на каждом из рядовых пунктов и базовом, где наблюдения велись непрерывно, позволяет производить учет внешних (солнечно-суточной и других) вариаций за счет высокой степени их идентичности в масштабах полигона ( 100 км). При проведении наблюдений в магнитоспокойное время суток (вечерние и ночные часы) величина неидентичности, как правило, не превышала 0,5 нТл. Это дает возможность определять пространственное распределение вековой вариации без расчета среднегодовых значений, как это делалось раньше по обсерваторским данным [Яновский, 1978].

Для выделения вековой вариации геомагнитного поля исследователи, как правило, используют 2 подхода. Первый заключается в расчёте вековой вариации по моделям главного магнитного поля (ГМП) как разности значений поля между соответствующими моментами времени. Одной из общепризнанных моделей ГМП является модель IGRF-12 
(International Geomagnetic Reference Field) [Erwan Thébault et al., 2015], которая описывает структуру геомагнитного поля и его вековых вариаций в глобальном и региональном масштабах. Минимальные выделяемые структуры геомагнитного поля по моделям IGRF составляют порядка 3 тыс. км, что соответствует высшим гармоникам в разложении ГМП по степеням $\mathrm{n}=12$ - 14 [Ладынин и др., 2005]. Поэтому для локальных полигонов различие значений геомагнитного поля, определяемое по модели IGRF-12 и по результатам измерений на конкретном полигоне, может быть значительным. Особенно это справедливо для районов Сибири, где сеть геомагнитных обсерваторий заметна реже, чем в европейской части России и, тем более, в Европе [Ладынин и др., 2006; Кулешов, Дядьков, 2013].

Исследования показывают, что модели IGRF, как и другие модели ГMП, не всегда позволяют выделить вековую вариацию с требуемой точностью. В работе [Демина и др., 2010] проведено исследование качества прогноза векового хода (изменение вековой вариации в конкретной исследуемой области за конкретный временной период) главного магнитного поля Земли, вычисленного по модели IGRF-10. Показано, что для территории России абсолютная ошибка прогноза с 2000 по 2005 гг. достигала величины - 300 нТл. Отклонение значений вековой вариации для обсерватории Арти (Урал) от рассчитанной по моделям IGRF за интервал 1965 - 2004 гг. достигало 120 нТл [Чурсин и др., 2008].

Приведенные выше факты указывают на недостаточный уровень точности определения ГМП и его вековой вариации по данным моделей IGRF (как и по любым другим глобальным моделям) в случае определения вековой вариации при высокоточных магнитных наблюдениях, выполняемых на отдельных участках земной поверхности. Особенно это актуально для тектономагнитных исследований, так как амплитуда тектономагнитных аномалий мала и обычно не превышает первых нТл.

Таким образом, основной целью предлагаемого исследования является определение параметров интерполирующей вековую вариацию поверхности по данным выполняемых высокоточных магнитных наблюдений.

\section{ИСТОЧНИКИ ВЕКОВОЙ ВАРИАЦИИ И ОЦЕНКА ЕЁ ПРОСТРАНСТВЕННОЙ НЕЛИНЕЙНОСТИ}

Источники вековой вариации. В настоящее время большинство исследователей сходится во мнении, что источником наблюдаемых на поверхности Земли изменений ГМП являются процессы, происходящие в жидком ядре. Авторы 
[Брагинский, 1978; Демина и др., 2008] предполагают, что в жидком ядре могут существовать квазистационарные структурированные течения, которым можно сопоставить систему источников. В силу того, что глубина до предполагаемых источников намного превышает их возможные размеры, в качестве таковых можно рассматривать диполи с определенными параметрами [Bartels, 1936; James, Winch, 1967; Калинин, 1969; Ладынин, Попова, 2009].

Особенности вековой вариации. Одним из характерных периодов вековых вариаций геомагнитного поля является период 60 лет. Структура фокусов 60 - ти летних вековых вариаций изоморфна и имеет пространственные размеры около 5 - 6 тыс. км. Величина этих фокусов составляет около 1500 - 2000 нТл. Абсолютная величина векового хода ГМП вблизи некоторых фокусов вековой вариации доходит 150 - 200 нТл/год. Возникают они преимущественно в средних широтах [Головков и др., 2010].

Карта вековой вариации геомагнитного поля для интервала 2000 - 2005 гг. [Macmilan and Quimp, 2000], на которой нами отмечено положение Алтайского полигона, показана на рис. 1.

\section{Оценка пространственной нелинейности вековой вариации в районе Восточно-} Сибирской мировой аномалии по данным модели IGRF-12. Выполнена оценка пространственной нелинейности вековой вариации геомагнитного поля по модели IGRF12 вдоль профиля А - B, пересекающего Восточно - Сибирскую магнитную аномалию и Алтайский полигон в направлении максимального пространственного градиента поля для эпохи 2010 г. (начало $45^{\circ}$ с.ш. и 70 в.д.; конец около $65^{\circ}$ с.ш. и $130^{\circ}$ в.д.). Длина профиля составила около 4000 км. Величина вековой вариации в зависимости от расстояния вдоль профиля приведена на рис. 2.

На участке профиля с 3000 до 3700 км, в области максимальной кривизны, пространственная нелинейность векового хода составила в среднем около 0,003 нТл*км/год. На участке Алтайского полигона ( 120 км) средняя величина нелинейности составила не более 0,001 нТл*км/год, а за весь исследуемый период 2004-2018 гг. на всем участке нелинейность составила 1,4 нТл, что является значимой и требующей учёта величиной при тектономагнитных исследованиях. Поэтому на Алтайском полигоне при выделении вековой вариации необходимо учитывать более высокие пространственные гармоники вековой вариации чем первая, которая соответствует плоскости. 


\section{ГЕОМАГНИТНЫЕ НАБЛЮДЕНИЯ НА АЛТАЙСКОМ ГЕОДИНАМИЧЕСКОМ ПОЛИГОНЕ}

Алтайский геодинамический полигон расположен в южной части Республики Алтай. Базовая магнитовариационная станция установлена в с. Акташ Улаганского района, где проводится непрерывная регистрация модуля вектора геомагнитной индукции начиная с октября 2003 г. Первые пункты тектономагнитных наблюдений были заложены спустя несколько дней после Чуйского землетрясения 27.09.2003 г., M=7.3 [Djadkov et. al, 2007]. Размеры полигона составляют порядка 120 на 110 км с севера на юг и с запада на восток соответственно. В настоящее время Алтайский геодинамический полигон включает около 40 рядовых пунктов наблюдений (рис. 3). Каждый пункт представляет собой жестко закрепленную относительно земной поверхности систему. По виду пункты делятся на 2 типа: 1) пункты, представляющие собой вкопанные деревянные постаменты, высотой около метра и диаметром первые десятки сантиметров; 2) жестко установленные в земле немагнитные репера с окопкой радиусом порядка 1 метра. На последних измерения проводятся на немагнитной треноге, устанавливаемой над центром репера на жестко фиксированной высоте (обычно h=100 см). Ошибка пространственной неточности установки датчика - не хуже 0,5 см, что при характерных пространственных градиентах аномального поля порядка 1 нТл/м будет соответствовать ошибке измерения не более 0,005 нТл.

Методика проведения магнитных наблюдений. Измерения модуля вектора индукции ГМП на пунктах Алтайского геодинамического полигона проводятся протонными магнитометрами на эффекте Оверхаузера (ММ-61, MB-08).

Среднеквадратическая погрешность измерений - не хуже 0.03 нТл. Долговременная нестабильность показаний - не хуже 0,2 нТл. Для исключения внешних геомагнитных вариаций используется базовая магнитовариационная протонная станция МВ-07 с такими же техническими характеристиками, которая устанавливается вблизи контрольного пункта наблюдений. При этом из результатов измерений на рядовых пунктах вычитаются синхронные значения магнитовариационной станции и, таким образом, исключается вклад внешних источников поля. Точность синхронизации измерений по времени не хуже 1 сек. (GPS датчики). При этом разности между величиной модуля вектора поля на пунктах и на базовой станции такие, что их среднеквадратичное отклонение находится для большинства пунктов в интервале 0,05-0,2 нТл для каждого цикла замеров (порядка 10-15 замеров с интервалом 20 сек). Специальные синхронные измерения в течение нескольких 
часов вечерне-ночного времени показали, что средний квадрат значений разности поля между наиболее удаленными пунктами и базовой станцией не превышает 0,5 нТл. Таким образом, обосновывается точность, с которой можно зафиксировать пространственные изменения вековой вариации на данном полигоне.

Выполнена оценка погрешности определения вековой вариации, обусловленной тем, что период проведения очередного ежегодного цикла измерений геомагнитного поля на Алтайском полигоне составляет около 10 - 14 дней, и не является одновременным для всех точек полигона. Эта погрешность составляет не более 0,05 нТл/100 км.

После исключения вклада внешних вариаций ГМП из значений поля каждого из пунктов вычитается значение контрольного пункта. Сравнивая полученные значения разностей геомагнитного поля на пункте наблюдения относительно контрольного, можно отследить динамику пространственного изменения поля, обусловленного внутренними источниками, в том числе вековой вариацией. Выявление тектономагнитных аномалий требует исключения вековой вариации, поскольку ее значения могут превышать величину искомых тектономагнитных аномалий, обусловленных внутрикоровыми процессами.

Для учёта вековой вариации нами предлагается методика, которая основана на использовании результатов регулярных высокоточных геомагнитных наблюдений на отдельных участках или полигонах.

\section{МЕТОДИКА ВЫДЕЛЕНИЯ ВЕКОВОЙ ВАРИАЦИИ ПО ДАННЫМ ВЫСОКОТОЧНЫХ НАБЛЮДЕНИЙ НА ЛОКАЛЬНЫХ УЧАСТКАХ}

Для выделения вековой вариации ГМП предложена следующая методика, которая использует известные модели ГМП в качестве основы для определения порядка поверхности, описывающей вековую вариацию. Под термином «локальный участок» понимается такой участок, размеры которого много меньше расстояния до источников вековой вариации (условно можно рассматривать число 10 как величину, характеризующую следующий порядок относительно единицы).

Подбор интерполирующей поверхности предлагается производить по следующей схеме.

1. На основе одной из общепринятых моделей ГМП, например, IGRF-12, строится карта вековой вариации за соответствующий период времени для исследуемой территории. 
2. По этим данным производится подбор порядка полиномиальной поверхности, который позволяет обеспечить необходимую точность интерполяции модельных данных.

3. На следующем этапе выбранный порядок полиномиальной поверхности используется для построения интерполирующей вековую вариацию поверхности, но уже по данным экспериментальных магнитных наблюдений, выполняемых на данном полигоне или участке.

Полученная в результате интерполирующая поверхность определяет близкую к реальной вековую вариацию на данном участке и может использоваться для её учёта при проведении геомагнитных наблюдений и магнитных съемок, выполняемых с различными целями.

Данная последовательность действий необходима, во-первых, для подбора порядка поверхности вековой вариации по данным глобальной модели ГМП а, во-вторых, для определения с использованием этого порядка параметров реальной вековой вариации по данным экспериментальных наблюдений на этом участке. При этом принимается во внимание точность наблюдений, необходимая для данного типа исследований.

Поскольку источники вековой вариации находятся на расстоянии не менее 3-х тысяч километров от поверхности Земли, а линейные размеры полигона, как правило, на порядок меньше, пространственное распределение вековой вариации должно быть гладким (не иметь локальных экстремумов на всей области полигона). Кроме этого, из-за относительного постоянства глубины источников, порядок поверхности будет определяться размерами полигона (участка), для которого подбирается функция, наилучшим образом описывающая вековую вариацию. По сути задача выделения вековой вариации на основе высокоточных геомагнитных данных сводится к разделению полей от локальных и региональных источников, когда процедурой осреднения исходных данных выделяется региональная составляющая, которая потом и исключается из исходных данных.

Важным аспектом является отбор пунктов для построения интерполирующей поверхности. Кроме операций, выполняемых для исключения выбросов и недостоверных значений магнитного поля, необходимо исключить из рассмотрения пункты, находящиеся в пределах влияния интенсивных магнитных аномалий (рис. 4) [ВСЕГЕИ, Карта аномального магнитного поля республики Алтай]. Дело в том, что в районах расположения аномально намагниченных массивов горных пород геомагнитные вариации вызывают индуктивные и ориентационные эффекты, которые могут достигать величин бо́льших, чем 
необходимая точность наблюдений при тектономагнитном мониторинге [Дядьков, 1985]. Вблизи пунктов не должно быть источников техногенных помех. Также требуется исключать из рассмотрения пункты, на которых наблюдаются тектономагнитные аномалии, отличающиеся, как правило, более коротким временным интервалом проявления, чем вековые вариации. В абсолютном большинстве случаев эти аномалии также приурочены к интенсивно намагниченным массивам горных пород ввиду линейной зависимости амплитуд магнитоупругого эффекта от величины намагниченности [Капица, 1955].

Таким образом, для выделения вековой вариации необходимо рассматривать только те пункты, которые в меньшей степени могут быть отягощены различного рода локальными эффектами, вызванными источниками в земной коре или источниками техногенной природы.

\section{ВЫДЕЛЕНИЕ ВЕКОВОЙ ВАРИАЦИИ НА АЛТАЙСКОМ ПОЛИГОНЕ. СРАВНЕНИЕ С МОДЕЛЬЮ IGRF-12}

\section{Подбор порядка полиномиальной поверхности, интерполирующей вековую} вариацию, с использованием модели IGRF-12. В соответствии с предложенной методикой был произведен расчет вековой вариации по данным модели IGRF-12 для территории Алтайского полигона. Затем, по полученным таким образом данным, был выполнен подбор типа поверхности (линейный, билинейный, квадратичный) и оценена величина невязки между данными, интерполированными полиномиальными поверхностями первых порядков, и данными значений вековой вариации, рассчитанными по модели IGRF-12 для пунктов Алтайского полигона. Получено, что максимальные величины среднеквадратичных отклонений исходных данных пространственного распределения вековой вариации за период 2004 - 2018 гг. (в координатах расположения пунктов) и интерполированных по модели IGRF-12 составили около 0,5 нТл в случае интерполяции плоскостью и около 0,1 нТл - в случае интерполяции квадратичной поверхностью. То есть, при интерполяции плоскостью остается недоучтенным вклад второй гармоники распределения поля. В связи с этим для интерполяции значений вековой вариации на территории Алтайского полигона выбрана поверхность второго порядка.

Расчёт вековой вариации по данным экспериментальных наблюдений. Следующий этап связан с определением параметров поверхности, наилучшим образом 
интерполирующей реальную вековую вариацию на Алтайском полигоне по данным экспериментальных высокоточных наблюдений.

Определение параметров вековой вариации геомагнитного поля для Алтайского полигона производилось по данным ежегодных магнитных наблюдений за период с 2004 по 2018 гг. При этом были выбраны пункты, расположенные вне влияния интенсивных магнитных аномалий, а также вне возможного влияния помех техногенного характера.

В соответствии с результатами предыдущего раздела была проведена интерполяция данных экспериментальных наблюдений поверхностью второго порядка (рис. 5).

Таким образом, как видно из рис. 5, максимальное расхождение величины вековой вариации, выделенной по данным наблюдений и по данным модели IGRF-12, составляет в направлении максимального градиента ее изменений в пределах Алтайского полигона ( 120 км) около 2 нТл за 14 лет, т.е., в среднем около 0,0013 нТл/(год*км).

Поскольку как при тектономагнитных исследованиях, так и при проведении магнитных съёмок, измерения проводятся относительно специально выбранных базовых пунктов, собственно абсолютная величина земного магнитного поля не влияет на искомые значения (тектономагнитные аномалии или аномальное магнитное поле). Тем не менее, представляет интерес вопрос о том, насколько измеренные абсолютные значения магнитного поля на Алтайском полигоне отличаются от рассчитанных по модели IGRF-12. Эти данные представлены на рис. 6, где показаны изменения абсолютных значений модуля вектора магнитной индукции (B) на пункте Медведь (Medved) по данным модели IGRF-12 и по результатам реальных измерений за период 2004 - 2018 гг., выполненных в первой половине августа в вечернее время суток. Несовпадение измеренных и модельных абсолютных значений поля в период 2004-2014 гг. составляет порядка 100 нТл. То обстоятельство, что реально измеренные значения ниже модельных, не позволяет объяснить это несовпадение недоучетом вклада магнитных источников в литосфере. В последние годы, 2015-2018 гг., наблюдается отличие характера изменений во времени абсолютных измеренных и модельных значений поля, по-видимому, связанное с тем, что значения для этого периода являются в модели IGRF-12 прогнозными. В отличие от близкого к линейному возрастанию поля по модели IGRF-12, реально измеренные значения после 2013-2014 гг. испытывают увеличение скорости роста.

Учёт вековой вариации ГМП на Алтайском геодинамическом полигоне. Обсуждение результатов. 
Максимальный градиент пространственного распределения вековой вариации, определенный для периода 2004-2018 гг. по данным наблюдений на полигоне и по модели IGRF-12 за период 2004 - 2018 гг., составил 31 нТл и 29 нТл на 120 км соответственно (рис. 5). Максимальные отличия значений вековой вариации, определенных по данным экспериментальных наблюдений на полигоне и по данным модели IGRF-12, составляют порядка 2-х нТл. Достаточно хорошая сходимость результатов может объясняться малыми значениями пространственной нелинейности вековой вариации в районе Алтайского полигона, что обусловлено относительной удаленностью этого участка от её фокусов (рис. 2). Несмотря на то, что это расхождение является сравнительно небольшим, полученные отклонения от реальных значений вековой вариации являются значимыми при тектономагнитных исследованиях и их необходимо учитывать.

Для учёта вековой вариации её значения, расчитанные по данным наблюдений на Алтайском полигоне для периода 2004 - 2018 гг., были вычтены из результатов наблюдений на каждом из пунктов, что позволило получить карту магнитных аномалий, источники которых расположены в земной коре (рис. 7). Карта построена с использованием программного пакета Surfer 10 (метод интерполяции - Kriging).

Учёт и исключение вековой вариации позволили выявить аномалии, которые до этой процедуры в явном виде не проявлялись. Экстремумы положительной аномалии в центральной части интенсивностью до 3 нТл пространственно приурочены к области основной сейсмодислокации Чуйского землетрясения 27.09.2003 г., Mw=7.3. Параллельно линии дислокации к северу от нёе выделяется отрицательная аномалия интенсивностью до 12 нТл. Природа этих аномалий требует отдельного рассмотрения и не является предметом изучения данной статьи, но их приуроченность к сейсмодислокации разрушительного Чуйского землетрясения может указывать на их связь с постсейсмческими процессами.

\section{ЗАКЛЮЧЕНИЕ}

Предложена методика учёта вековой вариации на основе данных высокоточных геомагнитных наблюдений на локальных участках земной поверхности, которая основана на том, что источники вековой вариации и источники поля в земной коре, вызванные геодинамическими процессами, имеют существенно отличающиеся глубины. Это позволяет интерполировать вековую вариацию полиномиальными поверхностями первых порядков и производить её учёт. 
Сравнение двух вариантов вековой вариации, рассчитанных по результатам высокоточных магнитных наблюдений на Алтайском геодинамическом полигоне и с использованием модели IGRF-12, показало их относительно хорошее соответствие ( 2 нТл за 14 лет), по-видимому, обусловленное удаленностью фокусов вековой вариации от этого региона. Однако выполняемые здесь наблюдения ввиду малых амплитуд тектономагнитных аномалий требуют более точного учета вековой вариации, что может обеспечить предложенная методика.

С использованием этой методики произведен учёт и исключение вековой вариации из данных высокоточных магнитных наблюдений на Алтайском геодинамическом полигоне за период 2004 - 2018 гг. Учёт вековой вариации позволил выделить локальные аномалии величиной до 12 нТл, которые до этого в явном виде не проявлялись.

Наблюдается пространственная приуроченность положительной аномалии величиной около 3 нТл к области сейсмодислокации Чуйского землетрясения 27.09.2003, Mw = 7.3.

Данная методика учёта вековой вариации является универсальной и применима при геомагнитных исследованиях и магнитных съемках, выполняемых с различными целями.

Работа поддержана проектом 0331-2019-0012 Госзадания и частично проектом РФФИ 17-05-01234 а.

\section{СПИСОК ЛИТЕРАТУРЫ}

Брагинский С.И. Геомагнитное динамо // Изв. АН СССР. Физика Земли, 1978, № 9, с. 74 $-90$.

Головков В. П., Яковлева С. В., Зверева Т. И. Выделение быстрых вековых вариаций по данным спутниковых магнитных съемок // Геомагнетизм и аэрономия, 2010, том 50, №2, с. $284-287$.

ВСЕГЕИ. Карта аномального магнитного поля республики Алтай. http://www.vsegei.ru/ru/info/gisatlas/sfo/altay/16-anom mag pole.jpg

Демина И. М., Королева Т. Ю., Фарафонова Ю. Г. Аномалии векового хода главного геомагнитного поля в рамках иерархической дипольной модели // Геомагнетизм и аэрономия, 2008, том 48, № 6, с. 849 - 858.

Демина И. М., Петрова А. А. Качество прогноза векового хода главного геомагнитного поля и его влияние на создание сводных карт аномального магнитного поля России // Вестник КРАУНЦ. Науки о земле. 2010 № 1. ВЫПУСК 15.

Дядьков П. Г. О линейности вторичных эффектов геомагнитных вариаций в аномальных полях при модульных измерениях // Геология и геофизика, 1985, №4, с. $129-136$.

Дядьков П. Г., Мандельбаум М. М., Татьков Г. И. и др. Особенности развития сейсмотектонического процесса и процессов подготовки землетрясений в Центральной части Байкальской рифтовой зоны по результатам тектономагнитных исследований. // Геология и геофизика, 1999, т. 40, №3, с. 346 - 359. 
Ладынин А. В., Попова А. А., Семаков Н. Н. Векторные измерения с феррозондовыми теодолитами. Новосибирский Государственный Университет, 2005, с 23.

Ладынин А. В. Попова А. А, Семаков Н. Н. Вековые вариации геомагнитного поля: сравнение спутниковых и наземных данных // Геология и геофизика, 2006, т. 47, №2, с. 278 - 291.

Ладынин А.В., Попова А.А. Оптимизационный подбор параметров эксцентричного диполя путем сравнения модельных полей с модельным полем Земли // Геология и геофизика, 2009, т.50 (3), с. 266 - 278.

Калинин Ю.Д. Определение параметров произвольно ориентированного магнитного диполя, представляющего геомагнитное поле // Геомагнетизм и аэрономия, 1969, т. IX, № $\quad$ 6, $\quad$ с. $1089 \quad$ - 1093. Капица С.П. Магнитные свойства эруптивных пород, подверженных механическим напряжениям // Изв. АН СССР. Сер. геофиз. 1955. № 6. С. 489.

Кулешов Д. А., Дядьков П. Г. Проблемы и методы учёта вековой вариации при проведении геомагнитных наблюдений и съемок в Сибири // Интерэкспо ГЕО-Сибирь2013, с. $171-175$.

Черняк Г.Я. О физической природе сейсмоэлектрического эффекта горных пород // Физика Земли. 1976. № 2. С. 108-112.

Чурсин А. В., Прутьян А. М., Федорова Н. В. Цифровая карта аномального магнитного поля Северного, Среднего и Южного Урала и прилегающих территорий Восточно-Европейской и Западно-Сибирской платформ // Литосфера, 2008, № 6, с. $63-72$.

Яновский Б.М. Земной магнетизм. Л., Изд-во Ленингр. ун-та, 1978, 592 с.

Barbot S., Hamiel Y. and Fialko Y. Space geodetic investigation of the coseismic and postseismic deformation due to the 2003 Mw7.2 Altai earthquake: Implications for the local lithospheric rheology // JGR, 2008, VOL. 113, B03403.

Bartels J. The eccentric dipole approximating the Earth's magnetic field // J.Geophys. Res., 1936, v. 41, p. 225 - 250.

Courtillot V., Mouël J.L.L. Time variations of the Earth's magnetic field: from daily to secular // Ann. Rev. Earth Planet. Sci. 1988. 16: 389-476.

Djadkov P.G., Mikheev O.A., Minenko M.I., Sobolev O.A. Some results of tectonomagnetic monitoring in the epicentral zone of the M7.5 Altay earthquake, September 27, 2003 // ANNALS OF GEOPHYSICS, 2007, vol 50 , p. $31-37$.

James R.W., Winch D.E. The eccentric dipole // Pure Appl. Geophys., 1967, v. 66, № I, $77-86$.

Macmilan S., Quimp J.M. The 2000 revision of the joint UK/US geomagnetic field models and an IGRF 2000 candidate model // Journal of Earth, Planet and Space, v.52, no. 12, 1149 - 1162. Nagata T. Tectonomagnetism // IAGA Bull. 1969. Vol. 27. P.12-43.

Thébault E, Finlay C. C., Beggan C.D. et al. International Geomagnetic Reference Field: 12-th generation // Earth, Planets and Space 2015, p. 67 - 79. 
Рис. 1. Карта изодинам главного геомагнитного поля $\mathbf{B}$ и его вековой вариации $-\mathbf{d B}$ для эпохи 2000-2005 гг. для территории Сибири и близлежащих областей по данным модели IGRF-8. Положение Алтайского полигона отмечено прямоугольником. Пунктирной чёрной линией A - В обозначена часть профиля, для которого оценивалась пространственная нелинейность вековой вариации. По [Macmilan and Quimp, 2000] с модификацией.

Рис. 2. Пространственное изменение вековой вариация $\mathrm{dB}$ по модели IGRF-12 вдоль профиля А - В (рис. 1), пересекающего Восточно-Сибирскую мировую аномалию (за период с 2004 по 2018 гг. относительно 2004 г.). Пунктирными линиями отмечены границы Алтайского геодинамического полигона.

Рис. 3. Схема пунктов геомагнитных наблюдений Алтайского геодинамического полигона. Звездой обозначен эпицентр Алтайского землетрясения 27. 09. 2003 г., M = 7.3. Черной линией отмечено положение основной сейсмодислокации по [Barbot et al., 2008].

Рис. 4. Карта аномального магнитного поля Горного Алтая. Черными точками обозначено положение пунктов тектономагнитных наблюдений. [ВСЕГЕИ. Карта аномального магнитного поля Республики Алтай].

Рис. 5. Пространственное распределение вековой вариации геомагнитного поля, интерполированное поверхностью второго порядка, относительно пункта «Медведь» (Medved) для Алтайского полигона за 2004 - 2018 гг. относительно 2004 г. А - данные наблюдений; В - данные модели IGRF-12; C - разность между А и В.

Рис. 6. Изменения абсолютных значений геомагнитного поля (В) на пункте Медведь (Medved) за период 2004 - 2018 гг. по данным экспериментальных наблюдений и рассчитанных по модели IGRF-12.

Рис. 7. Пространственное распределение изменений модуля вектора геомагнитной индукции dВ за период 2004 - 2018 гг на Алтайском полигоне относительно пункта «Медведь» (Medved) - ( А); (В) - вековая вариация, определенная по данным наблюдений на полигоне; (C) - изменение аномального магнитного поля, полученное после исключения вековой вариации. Звездой отмечен эпицентр Чуйского землетрясения 27.09.2003, M=7.3. Черной линией показана сейсмодислокация этого землетрясения (по [Barbot et al., 2008]). 


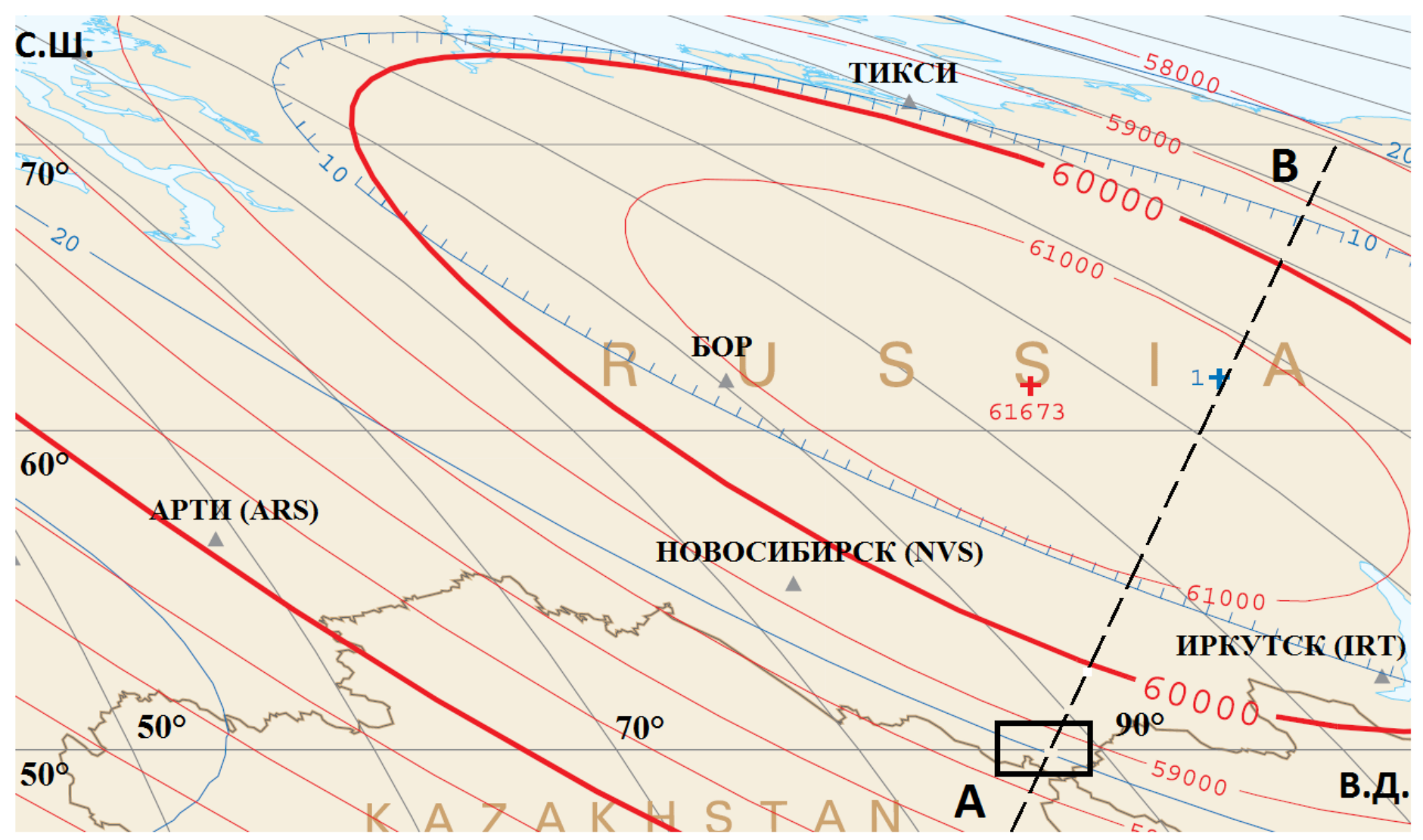

\section{ОБОЗНАЧЕНИЯ}

Геомагнитное поле

$-60000-$ Изолинии модуля вектора
геомагнитного поля в нТл

+ $\quad$ Величина модуля вектора главного

61373 геомагнитного поля в нТл

Данная точка обозначает положение максимума поля

А-В условный профиль

Положение Алтайского

геодинамического полигона
Вековая вариация

Изолинии вековой вариации главного геомагнитного поля в нТл

ш10ш Штрихи указывают направление убывания вековой вариации

$1+$ Величина вековой вариации геомагнитного поля в точке в нТл/год

Данная точка обозначает положение минимума вековой вариации (фокуса векового хода)

- Геомагнитные обсерватории, имеющие данные о величине геомагнитного поля как минимум с 1990 г. 


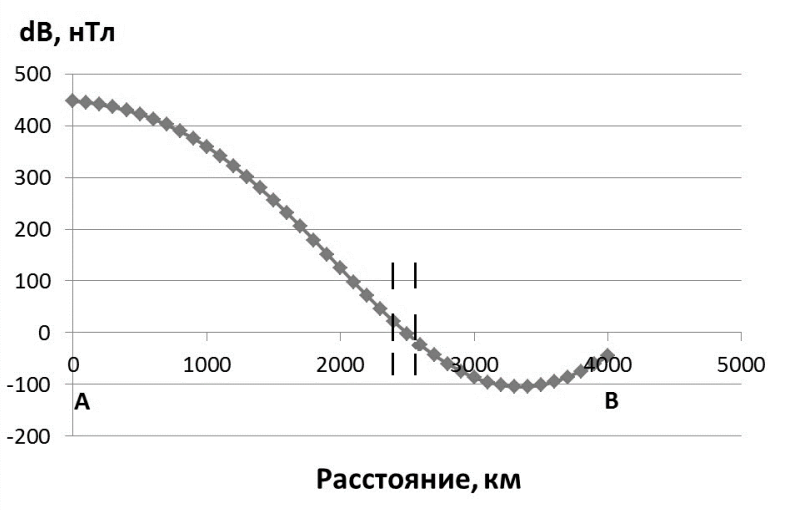




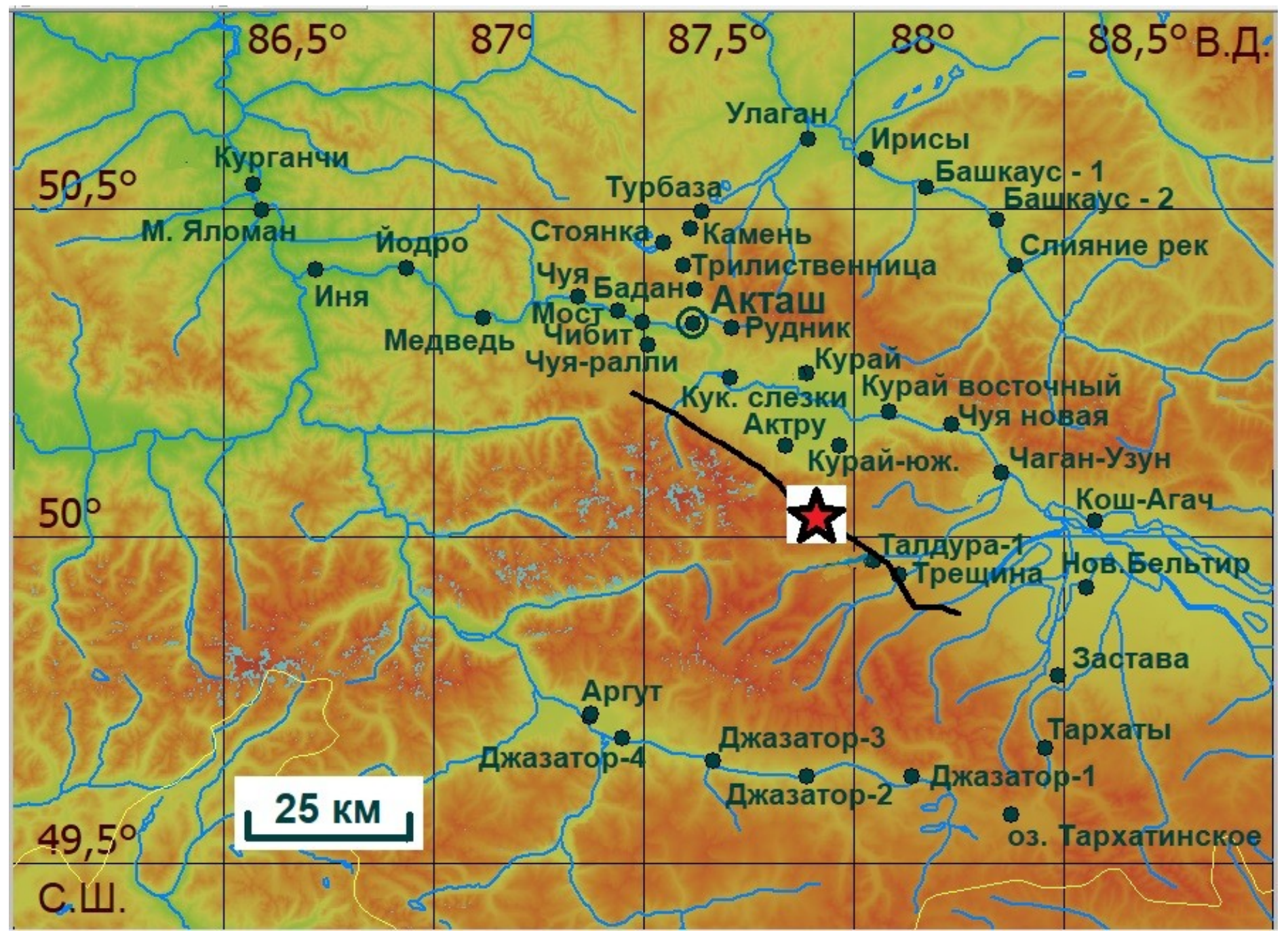




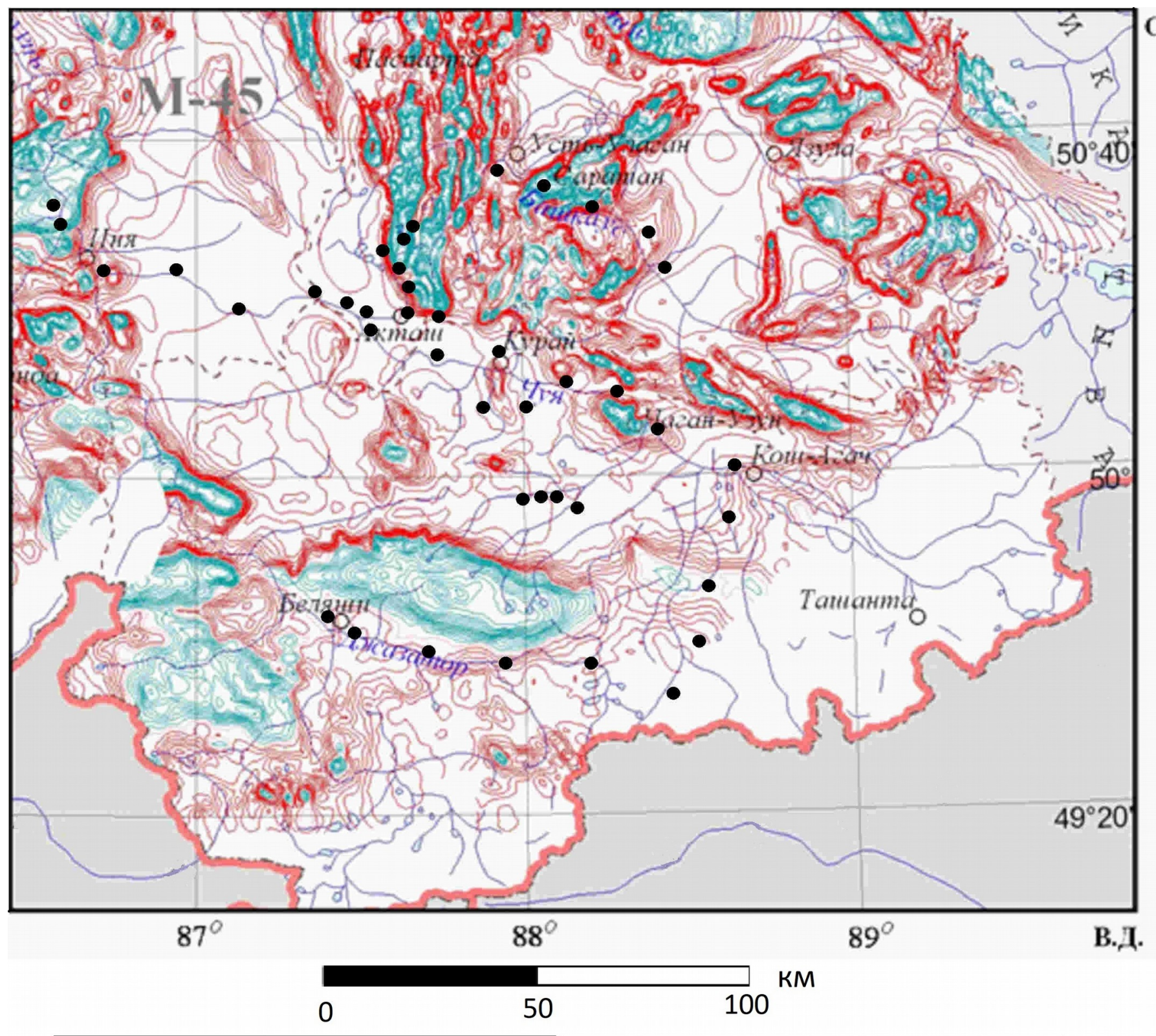

C.III.

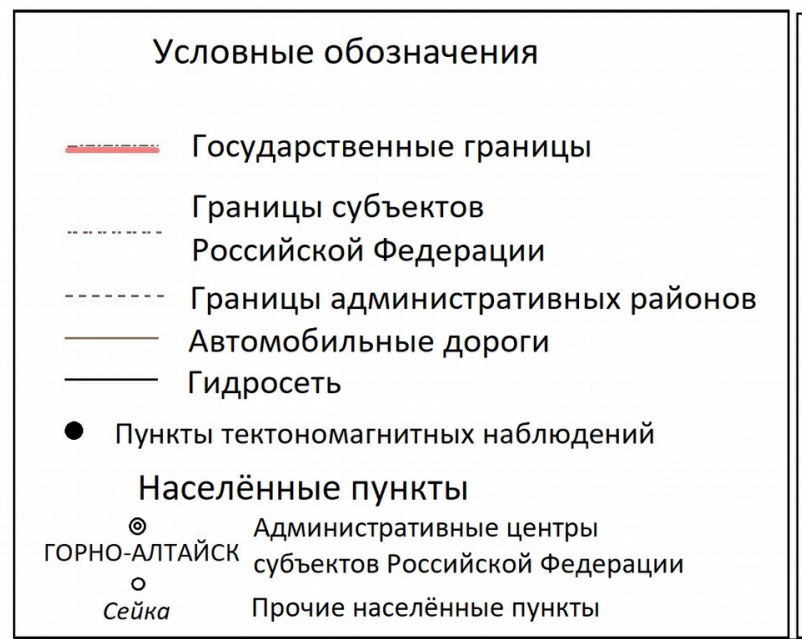

Шкала значений аномального магнитного поля $(\Delta \mathrm{T})$ а в $10^{-2}$ нТл

$-8 ;-7 ;-6 ;-4 ;-3 ;-2,5 ;-2 ;-1,75 ;-1,5 ;-1,25 ;-1$;

$-0,75 ;-0,5 ;-0,25 ; 0 ; 0,25 ; 0,5 ; 0,75 ; 1 ; 1,25 ; 1,5$;

1,$75 ; 2 ; 2,5 ; 3 ; 3,5 ; 4 ; 5 ; 6 ; 7 ; 8 ; 9 ; 10 ; 11 ; 12$; $13 ; 14 ; 15 ; 16 ; 17 ; 18 ; 19$

Изолинии аномального магнитного поля в $(\Delta \mathrm{T})$ а в $10^{-2}$ нТл

— отрицательные нулевые положительные 

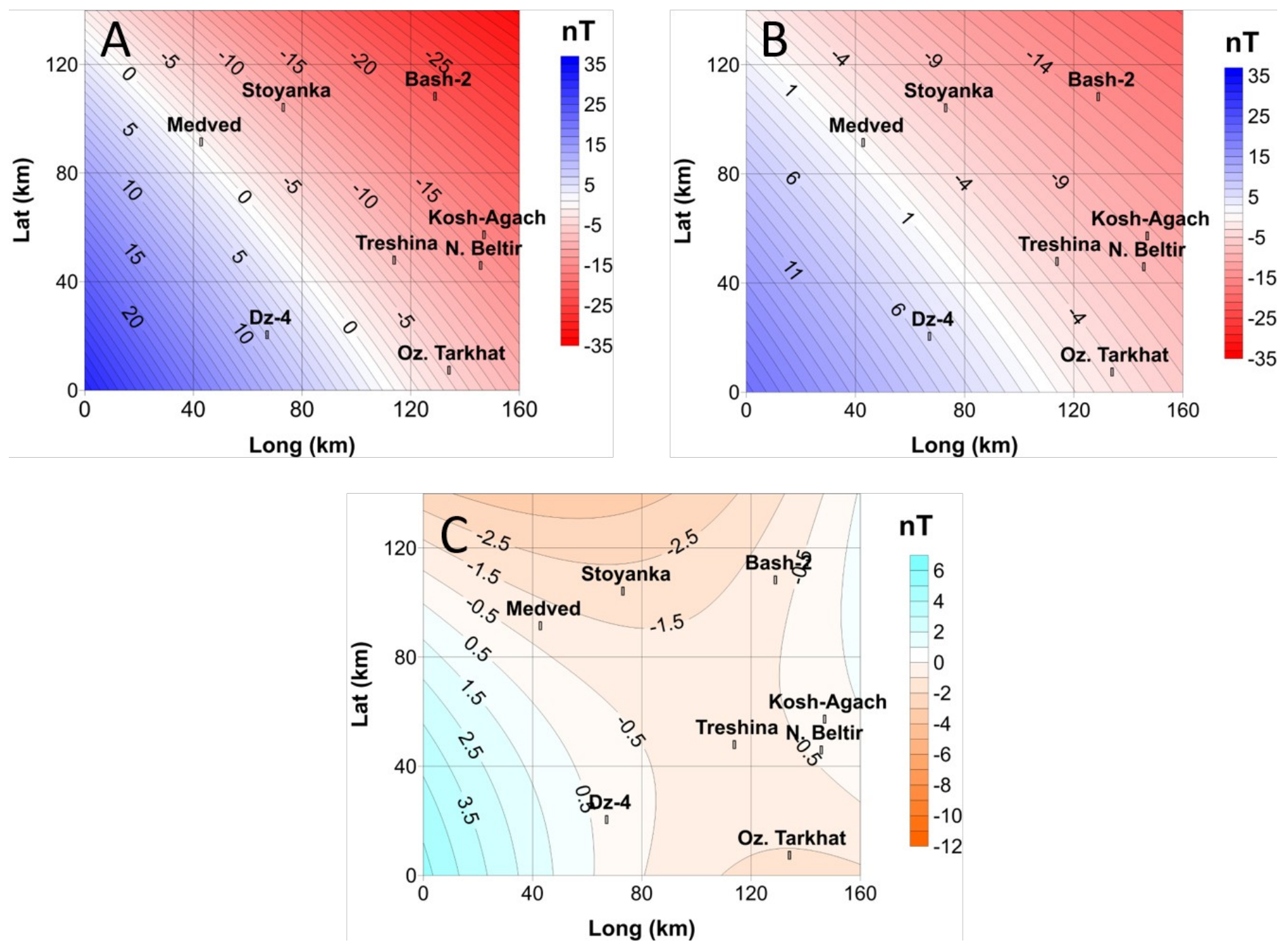


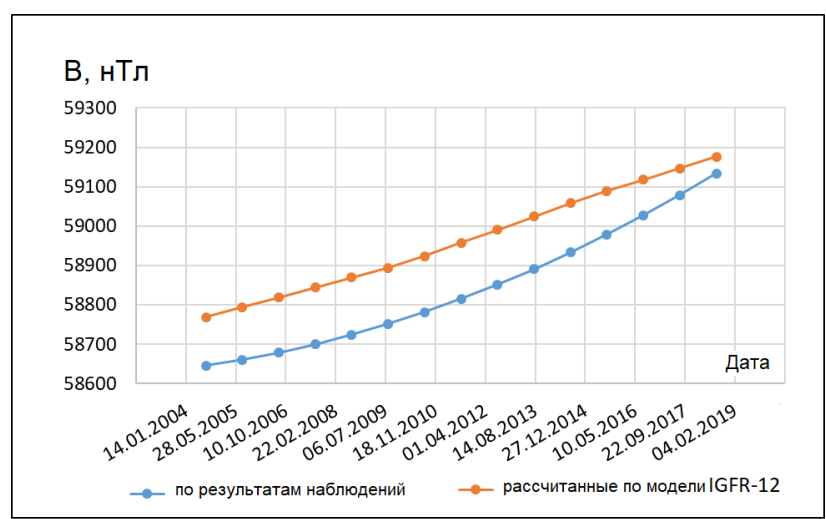



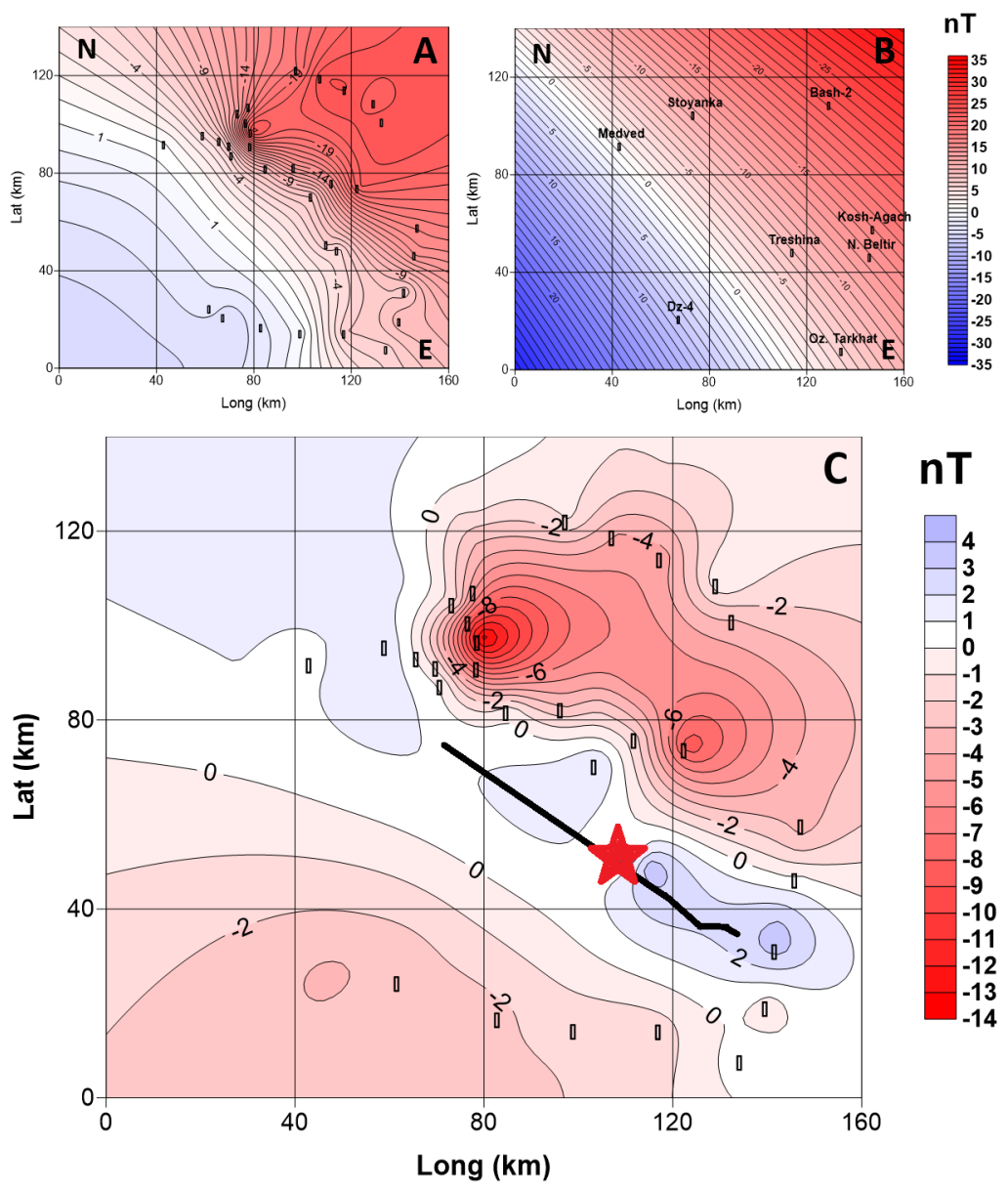